\title{
Preparation of Polyacrylonitrile-Kapok Hollow Microtubes Decorated with Cu Nanoparticles
}

\author{
Apollo Agcaoili ${ }^{1, a}$, Keiichi Ishihara ${ }^{2, b}$, and Mary Donnabelle Balela ${ }^{1, c}$ \\ 1 Sustainable Electronic Materials Group, Department of Mining, Metallurgical and Materials Engineering, University of the Philippines, 1101 \\ Diliman, Quezon City. \\ ${ }^{2}$ Graduate School of Energy Science, Kyoto University, Kyoto, 606-8501, Japan
}

\begin{abstract}
A novel copper $(\mathrm{Cu})$ nanoparticle carrier was fabricated using kapok natural microtubes as a substrate. $\mathrm{Cu}$ nanoparticles were grown on a thin polymer film on the surface of the kapok fibers. The polymer film was deposited on the surface of the microtube using a surfactant-assisted polymerization of acrylonitrile monomers. Cetyltrimethyl ammonium bromide (CTAB) was used surfactant. The contact angle decreased from 120.5 to 0 after polyacrylonitrile coating (PAN), which suggests improved hydrophilicity of the kapok fibers. Addition of $1.5 \mathrm{~mL}$ acrylonitrile and $0.020-0.035 \mathrm{~g}$ CTAB yielded evenly coated kapok fibers. $\mathrm{Cu}$ nanoparticles, with diameters of 82 $186 \mathrm{~nm}$, were formed on the surface of the composite by reducing $0.16 \mathrm{M}$ copper sulphate $\left(\mathrm{CuSO}_{4}\right)$ with hydrazine $\left(\mathrm{N}_{2} \mathrm{H}_{4}\right)$ at $70^{\circ} \mathrm{C}$. EDX reveals that more $\mathrm{Cu}$ nanoparticles formed on the surface of PAN-kapok composites with $0.035 \mathrm{~g}$ CTAB due to thicker PAN coating.
\end{abstract}

\section{Introduction}

Kapok (Ceiba pentandra) is a common species found in tropical countries. The kapok tree are characterized by its fruits or pods that releases low density fibers when ripe. The kapok fibers are unique in that they have a hollow lumen, giving them their microtubular structure [1]. The inner diameter of the kapok fibers is usually around 10$20 \mu \mathrm{m}$, while the wall thickness is about 1-2 $\mu \mathrm{m}$ [2]. Thus, kapok fibers have naturally superior surface area compared to other plant fibers The hollow tube of the fibers also makes it a desirable template material or support for catalysts $[1,3]$.

$\mathrm{Cu}$ nanoparticles have been receiving much attention because of its unique properties, as well as the simplicity of its synthesis process. $\mathrm{Cu}$ nanoparticles are also proven to be effective antimicrobial agents. Though the exact cytotoxic mechanism of the $\mathrm{Cu}$ particles is still unknown, various explanations have already been proposed in recent studies [4]. One of the more rational explanations is that when a bacterium comes in contact with a highly conducting surface (i.e. $\mathrm{Cu}$ ) its transmembrane potential is short-circuited. The released positively charged $\mathrm{Cu}$ ions from the nanoparticles can now easily invade the bacteria and disrupt its transmembrane charge balance. When disrupted, the bacteria can no longer produce energy, thus it is eventually killed [5]. On the other hand, $\mathrm{Cu}$ nanoparticles, when oxidized to $\mathrm{CuO}$, can also act as promising photocatalysts [6]. $\mathrm{CuO}$, when irradiated with light energy, can release $\mathrm{OH}$ radicals and oxygen super anions [6] that can help degrade organic pollutants, odors, and some known pathogens. $\mathrm{CuO}$ is a narrow band gap p-type semiconductor [7]. These $\mathrm{Cu}$-based nanoparticles, when anchored properly onto a template with high surface area, can potentially improve its applicability for water purification. The kapok fibers, a renewable and cheap resource, has high potential applications as $\mathrm{Cu}$ nanoparticle carriers. However, due to its naturally high hydrophobicity, its applications are limited without proper modification first.

In the study, the kapok fibers were coated with a thin film of PAN using a surfactant assisted method. PAN is also known as a heavy metal adsorbent [8] and would serve a dual purpose as anchors for $\mathrm{Cu}$ nanoparticles, as well as heavy metal adsorbent for water purification.

\section{Experimental}

\subsection{Materials}

Kapok pods were harvested from Rizal, Nueva Ecija, Philippines. The kapok hulls and seeds were removed in order to obtain the hollow fibers. Hexadecyltrimethylammonium bromide (CTAB, 99.0\%), potassium peroxodisulfate (KPS, 98.0\%), copper sulfate pentahydrate $\left(\mathrm{CuSO}_{4} \cdot 5 \mathrm{H}_{2} \mathrm{O}, 99.5 \%\right)$, hydrazine $\left(\mathrm{N}_{2} \mathrm{H}_{4}\right.$, $100 \%)$ and acrylonitrile monomer $\left(\mathrm{C}_{3} \mathrm{H}_{3} \mathrm{~N}\right)$ were

Corresponding author: ${ }^{\mathrm{a}}$ apolloagcaoili@yahoo.com.ph, ${ }^{\mathrm{b}}$ ishihara@energy.kyoto-u.ac.jp, ${ }^{\mathrm{c}}$ mlbalela1@up.edu.ph 
analaytical grade and purchased from Nacalai Tesque. Deionized water was used throughout the experiment.

\subsection{Deposition of thin PAN film onto kapok surface}

The method used was as suggested by Fan et al. with a few modifications [1]. The surfactant used to assist the polymer deposition was CTAB. $0.03 \mathrm{~g}$ of washed and dried kapok fibers were immersed in a CTAB solution for $1 \mathrm{~h}$. AN monomer was then injected to the solution and heat to $70{ }^{\circ} \mathrm{C}$ for $30 \mathrm{~min}$. Then, $0.06 \mathrm{~g}$ of KPS was then added to catalyse the polymerization process. The process was kept for $6 \mathrm{~h}$ under constant stirring. The PAN-coated fibers are then washed with deionized water and ethanol $\left(\mathrm{C}_{2} \mathrm{H}_{6} \mathrm{O}\right.$, Wako, $\left.99.0 \%\right)$ and then air-dried.

\subsection{Immobilization of $\mathrm{Cu}$ nanoparticles onto kapok-PAN microtube composites}

In a typical experiment, $0.01 \mathrm{~g}$ of the prepared and dried Kapok-PAN composites were immersed in $10 \mathrm{~mL}$ of $\mathrm{CuSO}_{4}$ solution for $1 \mathrm{~h}$. This was followed by immersion in $10 \mathrm{~mL}$ of $1 \%(\mathrm{v} / \mathrm{v}) \mathrm{N}_{2} \mathrm{H}_{4}$ solution at $70{ }^{\circ} \mathrm{C}$ for $10 \mathrm{~min}$ with constant stirring [9]. Afterwards, Cu-PAN-kapok were ultrasonically cleaned in deionized water for $5 \mathrm{~min}$ to remove agglomerated and poorly adhered $\mathrm{Cu}$ particles. The composites were then washed with ethanol and dried at room temperature.

\subsection{Characterization}

The surface morphology of the kapok fibers was observed in a scanning electron microscope (SEM, Hitachi SU6600). Elemental analysis was performed by energy dispersive X-ray spectrometer (EDX, BRUKER XFlash Detector 5010) attached to the SEM. The contact angle was measured by dropping a bead of deionized water on a flattened bundle of fibers and then taking a picture using Canon EOS600D. The angle was measured using a digital image processing software (ImageJ).

\section{Results and discussions}

Figure 1 shows the SEM images of kapok fibers before and after modification with PAN. Pristine kapok fibers have very smooth walls with a fully tubular structure having an inner diameter of 10 to $19 \mu \mathrm{m}$ and a wall thickness of 0.8 to $1.4 \mu \mathrm{m}$ as in Fig, 1(a). On the other hand, the SEM images show that the ratio of CTAB to AN significantly affects the resulting morphology of the PAN layer on kapok. If excess amount of AN is employed, non-uniform PAN coating is polymerized on the kapok surface as seen in Fig. 1(e)-(f). Similar results are observed after addition of low concentrations of CTAB. For example, large agglomerations with sizes that ranged from 3.16 to $32.19 \mu \mathrm{m}$ in diameter were formed when $2.85 \mathrm{~mL} \mathrm{AN}$ and $0.02 \mathrm{~g}$ CTAB is used as in Fig. 1(f). This is because the excess PAN that polymerized in the solution would assemble themselves onto the fiber. Since there is not enough CTAB to assist proper deposition, the PAN particles would randomly agglomerate onto the surface. With $1.50 \mathrm{~mL} A N$, increasing the $\mathrm{CTAB}$ concentration resulted in uniform but significantly thicker PAN coating. This suggests that CTAB concentrations controls the thickness of PAN. CTAB is able to arrange itself and coat the surface with positive charges. Higher CTAB concentration means more positive charges on the kapok surface, which could coordinate with more negatively charged PAN polymers. In samples with uniform PAN coating, a few aggregated PAN particles of about $472 \mathrm{~nm}$ in diameter were also observed on the surface of kapok. However, these aggregates could increase the effective surface area of kapok microtubes due to enhanced surface roughness. In all samples, however, the microtubular shape and hollowness of the fiber composites are preserved. (a)

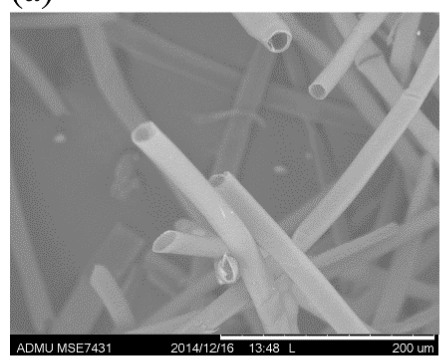

(d)

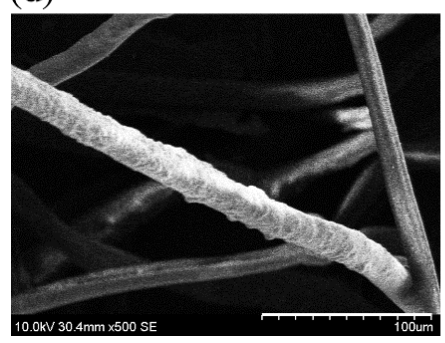

(b)

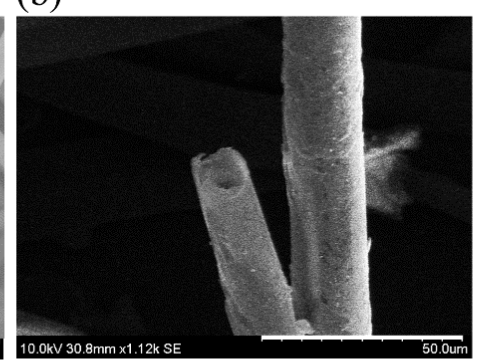

(e)

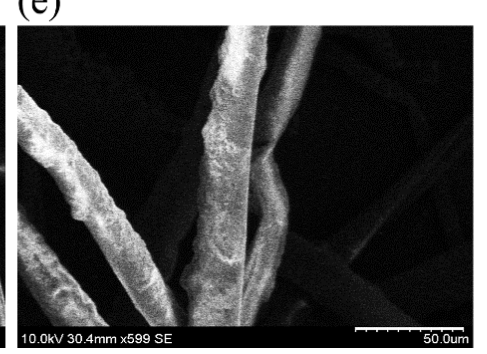

(c)

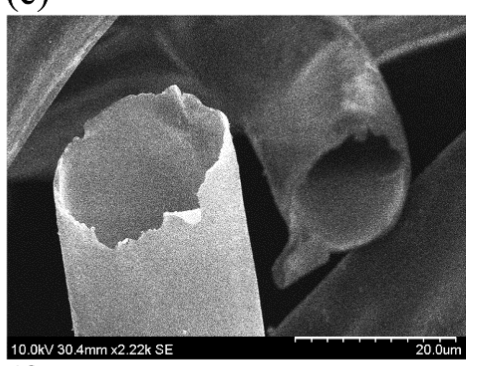

(f)

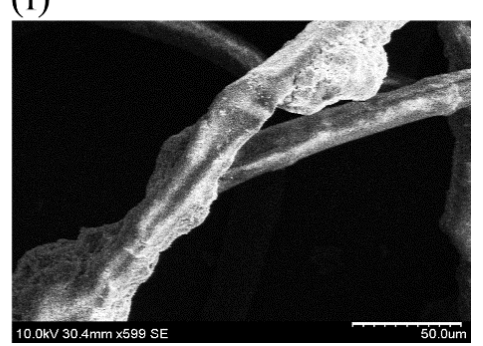


Figure 1. SEM images of (a) pristine kapok fibers and fibers coated with PAN using (b) $0.15 \mathrm{~mL} A N-0.02 \mathrm{~g}$ CTAB, (c) $1.50 \mathrm{~mL}$ $\mathrm{AN}-0.02 \mathrm{CTAB}$, (d) $1.50 \mathrm{~mL}$ AN $-0.035 \mathrm{CTAB}$, (e) $1.5 \mathrm{~mL} \mathrm{AN}-0.005 \mathrm{CTAB}$, (f) $2.85 \mathrm{~mL} \mathrm{AN}-0.02 \mathrm{~g}$ CTAB

Figure 2 shows the SEM images and the corresponding EDX spectra of Cu-PAN-kapok composites formed with different amount of $\mathrm{CTAB}$. The $\mathrm{Cu}$ nanoparticles on PAN-coated kapok fibers (1.5 mL AN - 0.02 g CTAB) are evenly distributed and have a mean diameter of about $134 \mathrm{~nm}$. Agglomerations of the particles, however, are also observed. On the other hand, the $\mathrm{Cu}$ nanoparticles that are grown using $1.5 \mathrm{~mL}$ AN- $0.035 \mathrm{~g} \mathrm{CTAB}$ are also uniformly dispersed on kapok surface and have a mean diameter of $125 \mathrm{~nm}$. Similarly, a few agglomerated $\mathrm{Cu}$ nanoaprticles are also present. On the other hand, the $\mathrm{Cu}$ peaks in the EDX spectra in Fig. 2 confirm the presence of $\mathrm{Cu}$ nanoparticles on the PAN-kapok surface. For the Cu-PAN-Kapok with $0.020 \mathrm{~g} \mathrm{CTAB,} 3.15$ wt \%

(a)

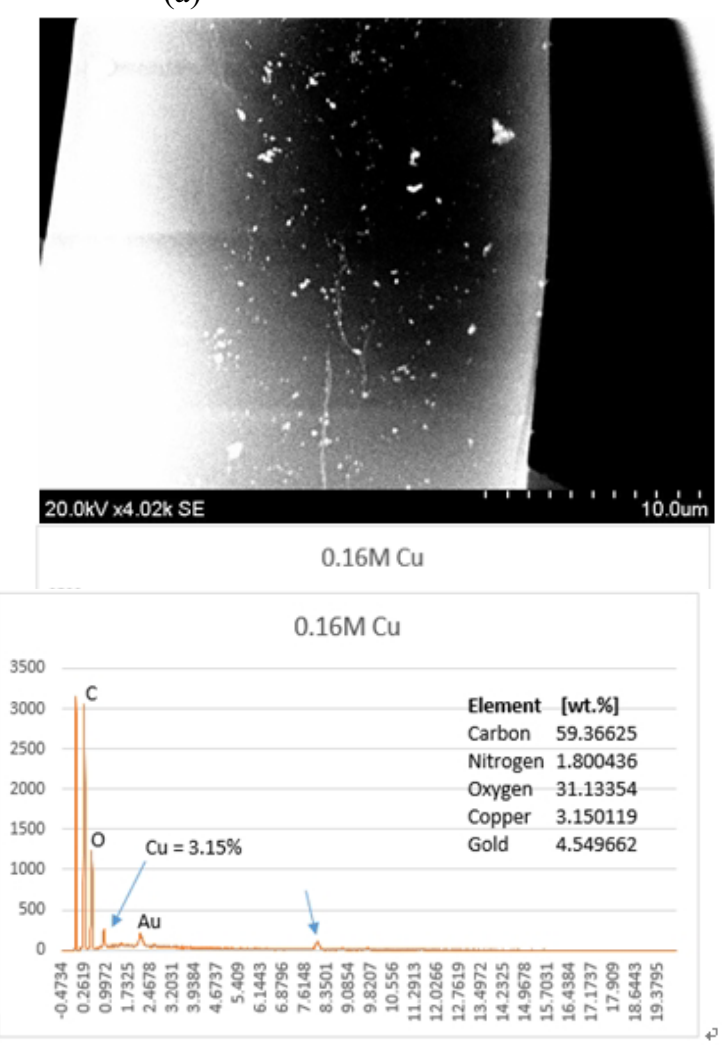

$\mathrm{Cu}$ was measured from EDX. On the other hand, an increase in the $\mathrm{Cu}$ content to $4.22 \mathrm{wt} \%$ was determined for the $\mathrm{Cu}-\mathrm{PAN}$ kapok composite with $0.035 \mathrm{~g}$ CTAB. This can be attributed to the thicker PAN film when higher amount of CTAB is added, which promotes $\mathrm{Cu}$ deposition. Further, nitrogen is also significantly higher in the sample with $0.035 \mathrm{~g}$ CTAB. This confirms that there is a higher PAN content in the fiber since nitrogen is an element found in the polymer coating. After immobilization of $\mathrm{Cu}$, the PAN coating on kapok appears smoother. This can be attributed to the ultrasonic cleaning after $\mathrm{Cu}$ deposition, which could have removed agglomerated PAN particles on the kapok surface.

(b)

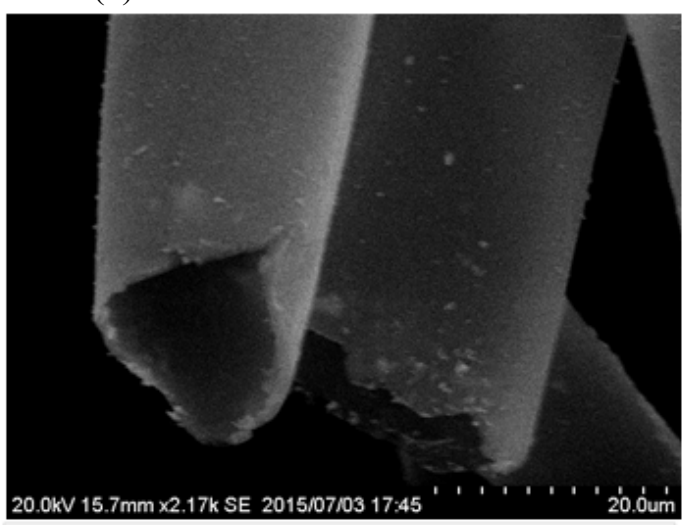

$0.16 \mathrm{M} \mathrm{Cu}$

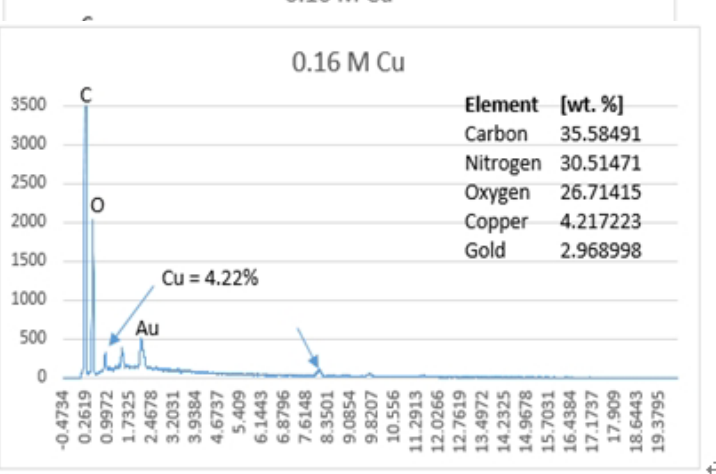

Figure 2. SEM and corresponding EDX spectrum of Cu-PAN-Kapok synthesized using 0.16 M Cu and (a) $1.5 \mathrm{Ml} \mathrm{AN}$ and $0.020 \mathrm{~g}$ $\mathrm{CTAB}$ and (b) $1.5 \mathrm{ml} \mathrm{AN}$ and $0.035 \mathrm{~g} \mathrm{CTAB}$

The contact angles measured for PAN-kapok fibers, before and after $\mathrm{Cu}$ nanoparticle deposition are listed in Table 1. Pristine kapok fibers are extremely hydrophobic as seen in Fig. 3. However, all PAN coated samples have 0 contact angle, which indicates that CTAB assisted PAN film coating is a very effective in creating thin hydrophilic films on kapok surface. Additionally, the fibers retained their hydrophilic properties even after $\mathrm{Cu}$ nanoparticle growth. This could be advantageous for water purifying applications.

\section{Conclusions}

Cu-PAN-Kapok composites were successfully synthesized using in-situ reduction of $\mathrm{Cu}$ (II) ion onto PAN coated kapok fibers. The fabricated materials are completely hydrophilic, which makes it a good material for water purification. The ratio of $\mathrm{AN}$ and CTAB has a significant effect on the uniformity and thickness of the PAN coating. Too high or too low AN relative to CTAB amount will result to highly irregular polymer films. The 
CTAB, on the other hand, has a larger effect on the film thickness. Additionally, thicker PAN coating results in large amounts of $\mathrm{Cu}$ nanoparticle grown.

Table 1. Contact angle of samples

\begin{tabular}{|l|l|}
\hline $\begin{array}{l}\text { Sample } \\
{\left[\mathbf{A N}(\mathbf{m L}) / \mathbf{C T A B}(\mathbf{g}) / \mathbf{C u}^{2+}(\mathbf{M})\right]}\end{array}$ & $\begin{array}{l}\text { Contact } \\
\text { Angle }(\mathbf{d e g})\end{array}$ \\
\hline Pristine kapok fibers & 120.5 \\
\hline $0.15 / 0.020 / 0.00$ & 0 \\
\hline $1.50 / 0.020 / 0.00$ & 0 \\
\hline $1.50 / 0.035 / 0.00$ & 0 \\
\hline $1.50 / 0.005 / 0.00$ & 0 \\
\hline $2.85 / 0.020 / 0.00$ & 0 \\
\hline $1.50 / 0.020 / 0.01$ & 0 \\
\hline $1.50 / 0.020 / 0.02$ & 0 \\
\hline $1.50 / 0.020 / 0.03$ & 0 \\
\hline $1.50 / 0.020 / 0.04$ & 0 \\
\hline $1.50 / 0.020 / 0.16$ & 0 \\
\hline $1.50 / 0.035 / 0.16$ & 0 \\
\hline
\end{tabular}

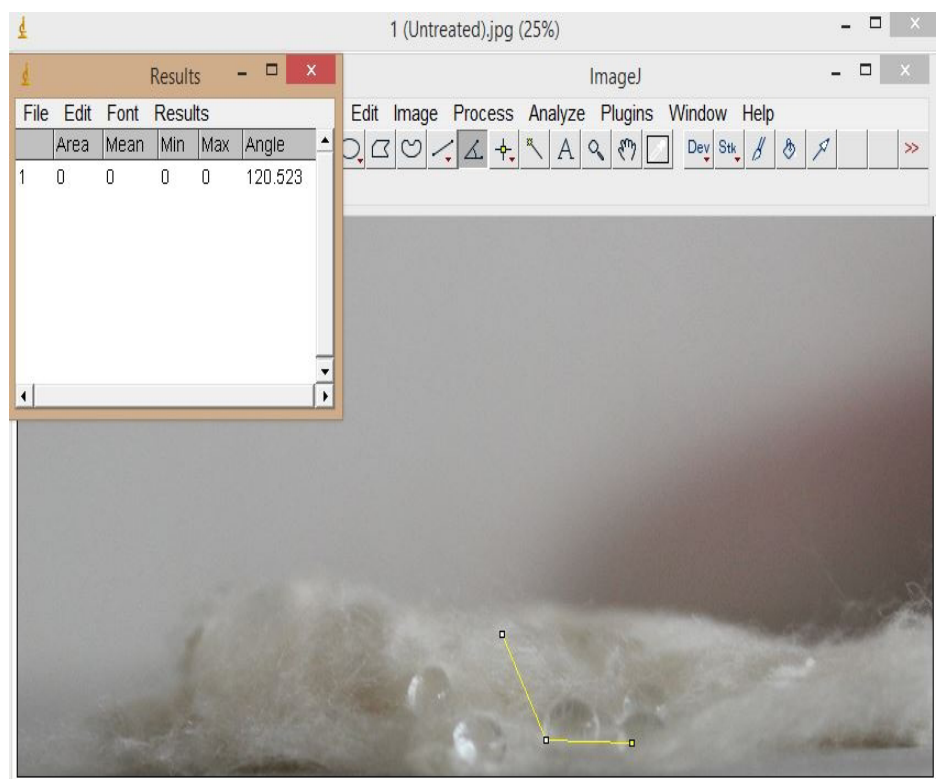

Figure 3. Contact angle measurement of pristine kapok fibers

\section{Acknowledgement}

The authors would like to thank DOST-PCIEERD, DOST-ERDT Scholarship Program, JASSO Student Exchange Support Program and the AUN-KU for providing research opportunities and funding.

\section{References}

1. Fan et al.: Preparation of kapok-polyacrylonitrile core-shell composite microtube and its application as gold nanoparticles carrier. Applied Surface Science, 258 (2012), pp. 2876- 2882.

2. X. Y. Zhang, C. T. Duan, N. Zhao, H. Xiao, M. W. Shi, X. L. Zhang, et al., Facile fabrication of large scale microtubes with a natural template-kapok fiber. Chin. J. Polym. Sci., 28, 5 (2010), pp. 841-847.

3. Wang et al., Enhanced Antibacterial Activity of Silver-Coated Kapok Fibers Through Dopamine Functionalization. Water Air Soil Pollut, 226 (2015).
4. J. Konieczny, \& Z. Rdzawski, Antibacterial properties of copper and its alloys, Archives of Material Science and Engineering, 56, 2 (2012), pp. 53-60.

5. Concha-Guerrero et al., Effect of $\mathrm{CuO}$ Nanoparticles over Isolated Bacterial Strains from Agricultural Soil. Journal of Nanomaterials, (2014), Article ID 148743.

6. T. Q. Chang, Z. J. Li, G. Q. Yun, Y. Jia and H. J. Yang, Enhanced Photocatalytic Activity of $\mathrm{ZnO} / \mathrm{CuO}$ Nanocomposites Synthesized by Hydrothermal Method. Nano-Micro Lett. 5, 3 (2013), pp. 163-168.

7. Yao et al.: Photocatalytic activity of $\mathrm{CuO}$ towards HER in catalyst from oxalic acid solution under simulated sunlight irradiation. Transactions of Nonferrous Metals Society of China, 20 (2010), pp. 1944-1949.

8. Pimolpun et al.: The Study of Competitive Adsorption of Heavy Metal Ions from Aqueous Solution by Aminated Polyacrylonitrile Nanofiber Mats. Energy Procedia, 56 (2014), pp. 142-151. 
9. M. S. Usman, N. A. Ibrahim, K. Shameli, N. Zainuddin, W. Zin, \& W. Yunus, Copper Nanoparticles Mediated by Chitosan: Synthesis and
Characterization via Chemical Methods. Molecules, 17 (2012), pp. 14928-14936. 